\title{
Socio-economic model of sustainable development
}

\author{
Gennady Rublev ${ }^{1, *}$, Lyudmila Bogdanova ${ }^{1}$, Svetlana Kurbatova ${ }^{2,3,4}$, Sergey Krasnousov ${ }^{3}$, \\ and Vladimir Kolmakov ${ }^{4}$ \\ ${ }^{1}$ Krasnoyarsk Institute of Railway Transport, Branch of Irkutsk University of Railways, Novaya \\ Zarya 2, Krasnoyarsk, 660028, Russia \\ ${ }^{2}$ Krasnoyarsk State Agrarian University, 90, Mira, Krasnoyarsk, 660042, Russia \\ ${ }^{3}$ Siberian Federal University, 79 Svobodny Ave., Krasnoyarsk, 660041, Russia \\ ${ }^{4}$ Krasnoyarsk State Medical University named after Prof. V. F. Voino-Yasenetsky, 1 Partisan \\ Zheleznyak Av., Krasnoyarsk, 660022, Russia
}

\begin{abstract}
The article considers the socio-economic model of sustainable development. The study analyzes the conceptual and theoretical foundations of the political, social, economic, spiritual, environmental, scientific, technical and information stability of the state and development of the socioeconomic system. The definition of the concept of the "sustainable state and development" was given, the structural model of the stability of the socioeconomic system was developed. The characteristics of the varieties of the sustainable state and development were defined. The prerequisites for further development of the theoretical foundations of the sustainable development of the socio-economic system were determined.
\end{abstract}

\section{Introduction}

The concepts of the sustainable state and development of the socio-economic system have been actively discussed in society since the end of the twentieth century and up to the present time, but their practical implementation is still a rather complex issue. This is due to the problems of sustainability of the social environment, in which the so-called "Gordian nodes" are: the concept of a stable state; its main properties, patterns and features; interactions between social systems at the regional and global levels; the evolution of the social system, etc.

Humanity develops in a society that has an impact on each individual at the same time. However, the person himself impacts the society, influencing its quantitative and qualitative changes. The stability of the socio-economic system can guarantee the effective development of both the society and humanity itself. Accordingly, the imbalance in relationships in society could cause the negative consequences, for example, an increase in the number of conflicts and the violation of the stability of the social environment. It is important to note that social life is always aimed at neutralizing various kinds of disturbances, both external and internal ones, and it also strives for the consensus within the society. All these issues are relevant in

\footnotetext{
* Corresponding author: gvrubl@mail.ru
} 
the problematic field of geopolitics and they determine the interest shown by the authors to the issues of stability of society.

\section{Materials and methods}

Taking into account the theoretical aspect and the socially significant nature of the issues raised in the article, we used methods of the theoretical level: abstraction, hypothetical (hypothetical-deductive) method, formalized, axiomatic, as well as the logical methods such as analysis, synthesis, analogy, etc. The knowledge of the essence of the issues raised, the connections between them, as well as the correctness of the results were defined with their help.

The system method contributed to the study of sustainability aspects of the development of societies as the independent socio-economic components, the relationship and interactions between them, processes, frameworks, and other characteristics, through which the particular understanding of the modern society, its sustainability and future trends were studied.

In the scientific disciplines of the natural profile, the definition of the term of stability is given by many researchers, but the most exact, in our opinion, is the interpretation of $\mathrm{A}$. Poincare [1]. In his opinion, the desire of a system taken out of equilibrium to return to this state, getting closer and closer to it - this is stability. In sociology [2], the stability of a system is understood as its ability to return to its original state after the termination of the influence that brought it out of this state. Therefore, the stability of the system reflects the immutability and its adaptation through changes. This characterizes the stable state of the system as a complex object of research, reflecting the internal structure of social relations and phenomena, its development and changes under the influence of external factors recorded in time and space.

\section{Results}

In our work, the structure of the stable state of the system is considered in the form of a formal model with its most significant elements. The varieties of the structure of this model selected on the basis of the system approach are shown in Figure 1. The integrity of the model is determined by the interdependence, interrelation and interaction of its elements. This model does not take into account the impact of the various factors on this system, due to the specifics of a certain stage of development of a particular society.

It is important to note that political stability is realized taking into account the diversity of the shades of the political situation of the current level of the development of the states in a multipolar world [3]. Today, the philosopher A. G. Dugin has developed the concept of the "dialogue of civilizations" for a multipolar world [4]. In this context, the pluralism of the international community becomes a new vector of development towards an intercivilizational balance of power.

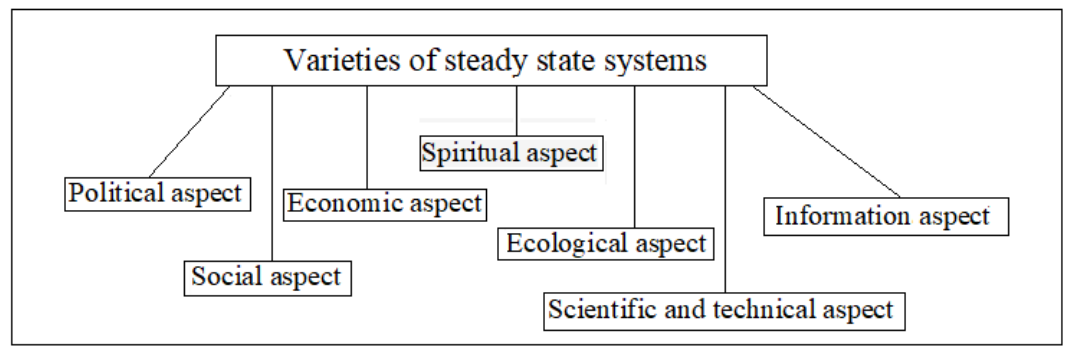

Fig. 1. Structure of the steady state model of the system. 
A number of authors [5] believe that under today's conditions, it is necessary to make the mechanism for maintaining the stability of a multipolar world. It should be noted that over the past thirty years, the political reality and the world politics have changed significantly not in the direction of building the stability of the international system. The new challenges of today, being the disturbing factors of the political environment, have led to the development of instability and the increased confrontation in the world.

It is important that the social environment always tends to balance, which is manifested in the stopping the disturbances and the desire to adapt to new conditions. The pursuit of harmony, order, consensus, solidarity, etc. are the important directions of its development. The stability of such a system is based on the desire of the society for harmony, solidarity, stability and it is ensured by the spread of traditional values, the dominance of positive feedback, under the influence of which the internal exchange is carried out. In this case, according to P. Sorokin [6], a constant tendency to its stabilization prevails in the system.

The social system combines all the manifestations of linear and nonlinear relationships. The social environment always tries to come to such a balance in order to neutralize all kinds of disturbances and adapt to new conditions. Thus, the social aspect of the sustainability of the system and its development is associated with the preservation of social stability through adaptation, self-regulation, order and reduce conflict, using all available stabilizing mechanisms, i.e., the processes of self-organization of the society are put into action. However, if we consider the situation from the other side, the conflict under the changed internal and external conditions can become a factor of integration and development of the system, as well as, an instrument of transformation and preservation of the social structure at the same time.

A steady state economy can be characterized as an economy with relatively stable main internal elements: population size and rationally used limited natural resources. In this interpretation, the economic aspect of the system's sustainability should be based primarily on its own resources, which is a self-supporting and strategic factor that reflects the key condition for any long-term development.

The economic sustainability of the system is related to the long-term balance between the exploitation of natural resources and the development of human society. From the standpoint of the evolutionary way of economic development, we can distinguish the life cycle of changes in the system, which depends on the environment of existence and which characterizes the constant change of processes in it [7].

The essence of such a cycle is as follows: the achievement of a stable state occurs after a period of growth or when a period of anti-growth (reduction) occurs. It turns out that during the transition from the stable state to an unstable one, a new situation arises in the economy.

Therefore, the stability of the economic system in a particular period is a state when its main characteristics (for example, financial, production, organizational ones, etc.) are within certain limits of stability, and under any changes in the external environment they are capable of development. In the " Concept of Sustainable Development "[8], adopted in 1987 in Rio de Janeiro, the sustainable development is understood as such development that contributes not only to improving the quality of life of people of the present and the future generations, but also to preserving a life-friendly environment. This concept focuses on two main interrelated concepts of needs and constraints. Constraints refers to the ability of the environment to meet the needs of humanity, both at present and in future. Thus, to analyze the stability and equilibrium of the system in the economy, the third parameter was used environmental one.

By now, when the anthropogenic impact on the environment is comparable to geological and geochemical processes, the issue of human survival is very acute. The increased level of consumption leads to the depletion of natural resources, environmental degradation and 
exacerbation of numerous environmental problems directly related to socio-economic development.

In our opinion, the spiritual component is designed to provide internal stability. Culture, being the bearer of the norms and the values, stabilizes and preserves society, acts as the main source of humanization of human history and ensures the unity of the value base in the socioeconomic system. For the preservation of culture, the dialogue of two cultures is important, when the new culture ("receiving") becomes the successor of the old one ("transmitting"). According to $\mathrm{Yu}$. M. Lotman [8], one culture transmits texts, and the other culture accepts and assimilates them, masters the "Varangian" language and recreates new texts according to similar rules. Thus, new cultural codes and traditions are gradually transmitted to the "receiving" party, which are dispersed and transformed in it. As a result, this culture gradually gets used to them, they become its own. This is a natural process of convergence and mutual influence of different cultures, and it has its own life cycle of development.

Another parameter of the spiritual aspect of the stable state of the system is the moral and ethical aspect, since it is through it that the stability of society is realized [9]. Spiritual life is a very subtle sphere of life of society and the state. As A. Toynbee [10] pointed out, spiritual culture is the foundation of civilization. Violation of the "culture-civilization" balance becomes the cause of crises (social, political, environmental, etc.), where the moral basis acts as a unifying principle.

The XX century was the century of technological realization of the numerous scientific discoveries of the previous generations, which ensured the high growth of the economy and the society. At the sustainable state and the development of the system, the scientific and technological progress is a natural stage of social and scientific development within the framework of the modernization of the human community [11], which has affected the various aspects of the modern society [12].

In our time, science and technology are the main factors of the development of society and, at the same time, they are the most important components of the development of productive forces. The scientific and technological progress, which influenced the efficiency of the economy, contributed to the growth of production, increased the level of well-being, and ensured the stability of society itself turned to be the main result of such processes.

At the same time, it is important to mention the main current trends, which are due to scientific and technological progress:

- development of the public institutions through the development of science, the greater use of technology in all the spheres of human activity, the innovation of production, management and education, etc.;

- the information technology and computerization;

- intensification of scientific research, integration and interchange of sciences;

- high degree of integration of science and technology, creation of world mass communication media, development of artificial intelligence;

- the increasing importance of the Internet for solving topical issues and influencing the nature of public relations $[13,14]$.

It is important that the socio-economic system, which is a set of logically interconnected various elements, the types and content of which are determined by the specifics of such a system, nevertheless, has a number of common properties, patterns and features.

As a result of the evolution of the development of society and its individual components, there is a complication of its structure, which is characterized by differentiation and integration.

At the same time, the development of the socio-economic system needs stability, variability and adaptation of the environment to disturbances. The considered model does not take into account the existing complexity of the world, in which the national fragmentation due to the original geographical situation, the destruction of the traditional 
forms of social contacts, moves towards the formation of the world community in the form of a global network structure.

\section{Discussion}

If the above-described aspects of the sustainable state and development of the socioeconomic system can be considered at the level of society, then, in our opinion, the spiritual aspect should be analyzed through the internal structure of a person that determines his behavior and activities.

In the center of the socio-economic system there is a man, and therefore his spiritual principles determined by the human nature, should be taken into account, factored in all these changes and transformations, not to be lost, but rather to grow and be developed based on the sustainability of socio-economic development of modern societies (figure 2). In this context, a person has an arbitrary activity and has his own goals, which may differ significantly from the interests of society. In particular, he determines independently his relations with the nature and social environment.

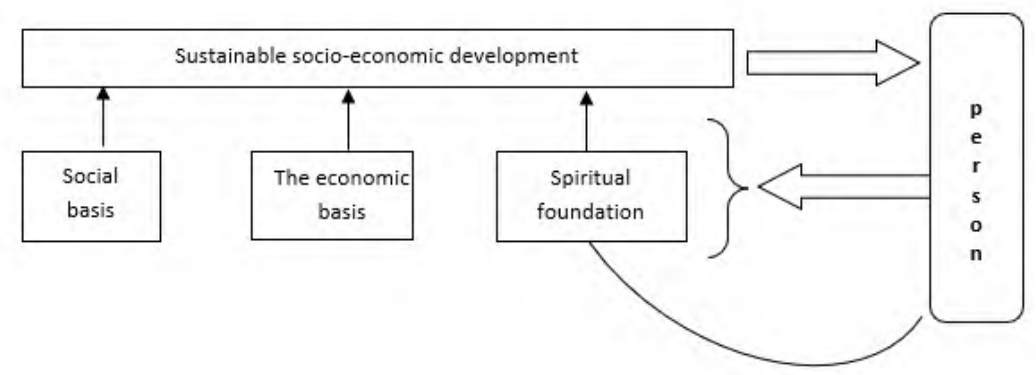

Fig. 2. Three parts-the basis of socio-economic interaction between the society and the individual.

Interacting, they form a three parts-basis of socio-economic interaction, which is focused on the person, but for this, initially, the person himself must ensure the proper quality of these foundations, which is a cyclical interaction (Figure 2). The defining principle in this interaction is precisely the person - human resources need the sustainable development of the society, but it is the people themselves who must ensure its stability and stability.

The authors proceed from the understanding that the development of any human community takes place in the noosphere, where the interaction of its three parts takes place:

- a society based on human and social resources;

- the ecosphere, which is the ecological shell of our planet, including natural resources (eternal, renewable and non-renewable);

- the technosphere, which is at the same time the source of human existence and forms its socio-cultural worldview.

Currently, due to the destructiveness of spiritual foundations, there is a contradiction in the interaction of society and nature: by the turn of the twentieth and twenty-first centuries, a socio-natural contradiction has clearly manifested itself, which refers to the main contradiction in the interaction of modern civilization with nature [15].

There is a conflict between the increased needs of the world community and the inability of the biosphere to meet them. And as a result, the most acute problems arise in an avalanche, such as: climate change, water scarcity and pollution, the disappearance of animal populations, the exhaustion of non-renewable resources, as well as many other negative consequences [16-18] that undermine the ability of the system to achieve "sustainable development" [19, 20]. 
And only through the awareness of humanity (real awareness, in fact, and not in words) of this whole situation it will be able to stop this destructive process, which will eventually affect people themselves, leading to the fact that it will no longer be about the sustainability of the socio-economic development of the society and the state, but about the need for simple survival $[20,21]$. And here the authors would like to draw attention to the spiritual basis, which is shown in Figure 2.

We believe that the harmonious development of this particular foundation will ensure the stability and development of social foundations, as well as the rational use of the foundations of economic-natural resources, technological developments and achievements, etc.

\section{Conclusion}

The article considers a formal model of the sustainable state and development of the socioeconomic system. The study used a systematic approach. The definition of the concept of "sustainable state and development" is given. The characteristic of the essence and content of the sustainable state and development is presented. The structure of stability of the socioeconomic system is developed. The conceptual and theoretical foundations of political, social, economic, spiritual, environmental, scientific, technical and information stability of the state and development of the socio-economic system were analyzed.

The prerequisites for further development of the theoretical foundations of sustainable development of the socio-economic system are determined.

Having analyzed the concepts, essence and properties of elements (varieties) of socioeconomic systems in relation to modern society, the authors focus on the following:

- modern society is a certain system of people and interactions between them, consisting of various socially significant elements that strive for sustainability while being ready for changes that bring these relationships to a new, higher level;

- modern societies and states are not always equivalent concepts, taking into account the processes of globalization that affect societies in the desire of states to preserve their political, geographical, economic, etc. independence and independence;

- there are trends towards the formation of macro-societies, as the current stage of human evolution is an increasingly complex social model, which is actively promoted by modern technologies and global network structures.

However, such a model still remains a socio-economic system and it strives for sustainability, which is provided by the social, economic, spiritual, political and other elements of the social system, which, again, is influenced by the person himself. The paper notes the importance of conscious interrelation of such subsystems of sustainable development as socio-economic and socio-political, which is also based on spiritual and humanistic principles.

The authors give special attention to the spiritual dimension through cultural and moral values and characteristics, based on the understanding of human nature as their owner and as a subject of socio-economic system.

\section{References}

1. A.G. Mikerov, Sources of the theory of stability of automatic control systems, Control Engineering Russia 3 (57), 90-93 (2015)

2. V. Osipov, Sociological encyclopedic dictionary (Moscow: Publishing house of the group "INFRA-M-NORM", 1998)

3. A.G. Dugin, The theory of a multipolar world (Moscow: The Eurasian movement, 2013) 
4. A.G. Dugin, Civilization:challenges of our time: collection of articles (St. Petersburg: Publishing House of St. Petersburg. Un-ta, 2009)

5. A.M. Samofal, Theoretical models of stability of international systems: History and modernity: Diss. sciences (St. Petersburg: St. Petersburg State University, 1999)

6. P. Sorokin, New materials for the scientific biography Sat. scientific. Tr. RAN. INION. Center for Social Science-inform. research Department of Sociology and Social Science. psychology Ed. Efremenko D V and Krotov P P (Moscow: INION RAN, 2012)

7. J. Xu, Z. Li, A review on ecological engineering based engineering management, Omega Elsevier 40, 3, 368-378 (2012)

8. Yu.M. Lotman, Agenda for the twenty-first century. Adopted by the UN Conference on Environment and Development, Rio de Janeiro, Memory of Culture (St. Petersburg: Iskusstvo-SPB, 2000)

9. O.V. Anrenko, A.N. Arlychev, V.M. Grinev, et al, Moral freedom of the will, The Modern moral discourse, Series Library of current philosophy (Krasnoyarsk, 2015)

10. A.J. Toynbee, Civilization before the court of history: A collection (Moscow: Rolf, 2002)

11. E.G. Markova, The essence, regularities and socio-economic consequences of the scientific and technical revolution, Questions of Historical Science: materials of the III International Scientific Conference Moscow 1-6 (2015)

12. L.V. Bertovsky, Digital legal proceedings: problems of formation Proceedings of materials of international scientific and practical conf «Problems of application of criminal and criminal procedure legislation» Simferopl 173-8 (2018)

13. G.V. Rublev, Abstracts of the XIX symposium "Complex Systems in Extreme conditions" (Krasnoyarsk: SFU, 2018)

14. E.V. Savorskaya, Political networks in the processes of supranational regulation: European and world experience (Moscow: IMEMO RAS, 2018)

15. F.A. Isatou, Sustainable development as a special state of interaction between society and nature: PhD thesis (Saransk: Publishing House of Un-ta, 1999)

16. A.V. Shamraev, T.S. Shorina, Influence of oil and petroleum products on various components of the environment, Bulletin of OSU 6, 642-643 (2009)

17. E.V. Karpenko, R.I. Vildanova, N.S. Shcheglova, T.P. Pirog, I.N. Voloshina, Perspective of using bacteria of the genus Rhodococcus and microbial surfactants for degradation of oil pollution, Applied biochemistry and Microbiology 42, 2, 175-179 (2006)

18. S.-H. Lee, et al, Effect of various amendments on heavy mineral oil bioreme-diation and soil microbial activity, Bioresource Technology 99, 2578-2587 (2008)

19. S.M. Kurbatova, L.Yu. Aisner, V.V. Naumkina, Some legal aspects of environmental engineering Proc.of the 2nd Int. Sci. Conf. AGRITECH-II-2019: Agribusiness, Environmental Engineering and Biotechnologies 421(Institute of Physics and IOP Publishing Limited) (2020)

20. M.A. Vaques, Soil pollution and decontamination in Spain, European Environmental Law Revie 11, 6, 174-185 (2002)

21. D.A. Agapov, O.Yu. Ganyukhina, Environmental management in Russia, Agricultural and land law 12 (169), 99-105 (2018) 